\title{
A systematic review of seroma formation following drain-free mastectomy
}

Citation for published version (APA):

De Rooij, L., Bosmans, J. W. A. M., van Kuijk, S. M. J., Vissers, Y. L. J., Beets, G. L., \& van Bastelaar, J. (2021). A systematic review of seroma formation following drain-free mastectomy. European Journal of Surgical Oncology, 47(4), 757-763. https://doi.org/10.1016/j.ejso.2020.10.010

Document status and date:

Published: 01/04/2021

DOI:

10.1016/j.ejso.2020.10.010

Document Version:

Publisher's PDF, also known as Version of record

Document license:

Taverne

Please check the document version of this publication:

- A submitted manuscript is the version of the article upon submission and before peer-review. There can be important differences between the submitted version and the official published version of record.

People interested in the research are advised to contact the author for the final version of the publication, or visit the DOI to the publisher's website.

- The final author version and the galley proof are versions of the publication after peer review.

- The final published version features the final layout of the paper including the volume, issue and page numbers.

Link to publication

\footnotetext{
General rights rights.

- You may freely distribute the URL identifying the publication in the public portal. please follow below link for the End User Agreement:

www.umlib.nl/taverne-license

Take down policy

If you believe that this document breaches copyright please contact us at:

repository@maastrichtuniversity.nl

providing details and we will investigate your claim.
}

Copyright and moral rights for the publications made accessible in the public portal are retained by the authors and/or other copyright owners and it is a condition of accessing publications that users recognise and abide by the legal requirements associated with these

- Users may download and print one copy of any publication from the public portal for the purpose of private study or research.

- You may not further distribute the material or use it for any profit-making activity or commercial gain

If the publication is distributed under the terms of Article $25 \mathrm{fa}$ of the Dutch Copyright Act, indicated by the "Taverne" license above, 


\title{
A systematic review of seroma formation following drain-free mastectomy
}

\author{
L. De Rooij, MD ${ }^{a}{ }^{*}$, J.W.A.M. Bosmans, MD, PhD ${ }^{a}$, S.M.J. van Kuijk, PhD ${ }^{b}$, \\ Y.L.J. Vissers, MD, PhD ${ }^{\text {a }}$, G.L. Beets, MD, PhD ${ }^{\text {c, d }}$, J. van Bastelaar, MD, PhD ${ }^{\text {a }}$ \\ a Department of Surgery, Zuyderland Medical Center, Sittard, the Netherlands \\ ${ }^{\mathrm{b}}$ Department of Clinical Epidemiology and Medical Technology Assessment, Maastricht University Medical Center, Maastricht, the Netherlands \\ ${ }^{\mathrm{c}}$ Department of Surgery, Netherlands Cancer Institute, Amsterdam, the Netherlands \\ d GROW School for Oncology and Developmental Biology, University of Maastricht, Maastricht, the Netherlands
}

\section{A R T I C L E I N F O}

\section{Article history:}

Received 28 July 2020

Received in revised form

14 September 2020

Accepted 9 October 2020

Available online 10 October 2020

\section{Keywords:}

Drain-free

Mastectomy

Seroma formation

Seroma aspiration

\begin{abstract}
A B S T R A C T
Background: Seroma is a common complication after mastectomy. The aim of this review is to elucidate whether closed suction drainage can safely be omitted in patients undergoing mastectomy when assessing seroma formation and its complications. The second aim is to assess the influence of flap fixation on seroma related complications, as there is existing evidence showing that combining mastectomy with flap fixation may make the use of drainage systems obsolete.

Search \& selection: A review of the literature was performed and articles that compared mastectomy with drainage and mastectomy without drainage were selected. Due to the small number of eligible studies, no selection based on whether flap fixation was performed was possible. If outcome was described in terms of seroma formation or seroma related complications, papers were eligible for inclusion. Studies older than 20 years, animal studies, studies not written in English and studies with male patients were excluded.

Results: A total of eight articles were eligible for inclusion. Four prospective studies and four retrospective studies were included. In four studies, flap fixation was performed. Frequency of seroma formation as well as seroma that required intervention was reported. The included studies demonstrated that omitting closed suction drainage does not lead to a higher incidence of seroma formation in patients undergoing mastectomy.

Conclusion: Despite substantial heterogeneity, there is evidence that drainage can safely be omitted without exacerbating seroma formation and its complications. A well-powered, randomized controlled trial evaluating the effect of drainage omission on seroma formation, with or without flap fixation, is needed.
\end{abstract}

๑ 2020 Elsevier Ltd, BASO The Association for Cancer Surgery, and the European Society of Surgical Oncology. All rights reserved.

\section{Introduction}

Seroma is a collection of serous fluid containing blood plasma and/or lymph fluid and is a common complication in breast cancer surgery [1-4]. With an incidence of up to $85 \%$, it is often considered to be an almost inevitable consequence of mastectomy [5-7]. The extent of seroma varies substantially; in some cases intervention is

DOI of original article: https://doi.org/10.1016/j.ejso.2020.10.019.

* Corresponding author. Zuyderland Medical Center, Department of Surgery, P.O. Box 5500, 6130 MB, Sittard, the Netherlands.

E-mail address: l.derooij@zuyderland.nl (L. De Rooij). required while in other it can be treated conservatively.

Seroma can lead to wound complications, patient discomfort and repeated visits to the outpatient clinic. Many studies have therefore focussed on the pathophysiology and the prevention of seroma formation and its sequelae. For many years, closed suction drainage has been considered to be the gold standard for reducing seroma formation after breast cancer surgery. There is ample conflicting evidence with regards to drain use after mastectomy. This raises questions why drains are so routinely implemented. Evidence of the effect of omitting closed suction drainage is conflicting with regards to incidence of seroma formation and volumes of seroma in the post-operative period [8-14]. Some studies conclude 
that the use of closed suction drainage in mastectomy patients leads to a longer postoperative hospital stay and that the length of closed suction drainage is related to a higher incidence of seroma formation [15-17].

One of the key elements to reduce seroma formation is the obliteration of dead space [1-4]. Mastectomy with flap fixation has evolved over the past few years and use of flap fixation is slowly increasing [17]. Flap fixation or quilting is a procedure where the mastectomy skin flaps are secured to the underlying pectoral muscle using sutures or tissue glues. Studies on flap fixation show promising results with regards to the reduction of seroma formation and seroma aspiration after mastectomy [18-26]. Mastectomy combined with flap fixation, is still often combined with closedsuction drainage [18-26]. A number of case series suggest that with flap fixation the omission of drainage systems does not lead to an increase in complications $[23,27,28]$. Given the potential of flap fixation in reducing seroma formation, closed suction drainage may no longer be necessary in clinical practice. In order to evaluate if closed suction drainage could safely be omitted following mastectomy, this systematic review was performed. Moreover, if there is compelling evidence in existing literature that postmastectomy drainage is unnecessary, this could be used to formulate guidelines. The role that flap fixation plays in enabling the omission of postmastectomy drainage should also be analyzed.

\section{Methods}

This systematic review was performed according to the recommendations of the systematic reviews and meta-analyses (PRISMA) guideline [29]. A review of the literature was performed to identify studies on breast cancer patients undergoing mastectomy in whom drainage was omitted. Medline, Embase, CINAHL and Cochrane Library were searched for the following MESH terms: 'mastectomy', 'breast', 'surgical procedures, operative' and 'drainage'. The full electronic search strategy for Medline comprised the following: (("Mastectomy, Modified Radical"[Mesh]) OR ("Mastectomy"[Mesh]) OR (Mastectom*[tiab] OR mrm[tiab] OR mammectom*[tiab] OR "breast amputation"[tiab] OR "breast resection"[tiab] OR "ampution of the breast"[tiab])) AND (("Drainage"[Mesh]) OR (drain*[tiab])). This resulted in papers published between 1954 and July 2019 for all databases. The primary search was conducted in July 2019 and since then a monthly update provided by Medline of new publications was screened for eligible articles. Adding additional search terms such as 'seroma' and 'adhesives' decreased the sensitivity of the search and were therefore omitted. The main outcome measure of this review was symptomatic seroma. Symptomatic seroma was defined as seroma requiring any form of surgical intervention. Seroma related complications are secondary outcomes.

\section{Selection criteria}

Inclusion criteria

Prospective and retrospective studies reporting on breast cancer patients undergoing mastectomy with or without axillary lymph node dissection were included in this review. Studies that compared mastectomy with drainage to mastectomy without drainage were selected. Papers were eligible for inclusion if outcome was described in terms of seroma formation and/or seroma related complications.

\section{Exclusion criteria}

Studies that were 20 years or older were excluded, as were papers not written in English and papers regarding animal studies. Studies involving patients undergoing direct breast reconstruction were also excluded.

Studies that evaluated differences between patients undergoing mastectomy and wide local excision were not excluded from the outset. However, only the relevant results of the patients undergoing mastectomy and/or modified radical mastectomy of these studies are discussed in this review.

\section{Data collection and analysis}

Two authors (LdR, JWAMB) independently performed the search and selection of papers. The first selection was based on screening of title and abstract. Final selection of eligible papers was made after full reading. The final decision was made by a third author (JvB) in case of disagreement in selection between the reviewing authors. Eligible reports were assessed on clinical and methodological quality. Assessment of the generation of random sequence, concealment of allocation and blinding of allocation was undertaken in case of a randomized controlled trial. The risk of bias in the included randomized controlled trials was assessed with the modified Cochrane Collaboration Risk of Bias Tool (Table 1) [30]. In case of a non-randomized study the risk of bias was assessed with the Risk of Bias In Non-randomized Studies - of Interventions (ROBINS-I) assessment tool (Table 2) [31]. Cross-referencing of the bibliography of selected articles was performed.

The following data were extracted from included studies: author, year, in- and exclusion criteria for patients, procedure of mastectomy, formation of symptomatic seroma and surgical site infection (SSI) rate, whether flap fixation was performed; symptomatic seroma was defined as seroma that required intervention.

Between-study heterogeneity was expressed as I-squared, which estimates the variation between studies due to actual heterogeneity rather than chance [32]. In case of substantial heterogeneity (i.e., I-squared > 50\%), we used a random effects model meta-analysis to pool results from multiple studies into a single inference. Measures of association were expressed as odds ratio (OR) and 95\% confidence interval (CI). The meta-analysis was performed using Review Manager (RevMan) [Computer program] (Version 5.3. Copenhagen: The Nordic Cochrane Centre, The Cochrane Collaboration, 2014).

\section{Results}

The search resulted in 1628 papers. Based on title and abstract, 1599 articles were excluded, resulting in 29 articles for further evaluation. Of these articles, 11 articles focused on drain-free mastectomy versus mastectomy with drain. Eighteen articles were excluded as these focused on non-published data (13), did not meet the research question (2), were not written in English (1), or concerned correspondence (1) or a methodological mini-review (1). Additionally, 3 studies were excluded. Two studies were excluded based on their non-comparative nature [33,34] and the third study was excluded since it did not report on the primary outcome of the current review [35]. Of the 8 studies that were selected for the review, 4 were prospective in nature and 4 were retrospective (Fig. 1). The selected articles were cross-referenced but this did not lead to additional eligible articles. In Table 3, an overview is given of the selected articles in chronological order with the incidence of seroma and clinically significant seroma per study. With the latter defined as any seroma that required intervention. As SSI was the seroma related complication that was most uniformly defined and was reported in seven of the eight reports, this parameter was chosen as the secondary outcome.

Baker et al. performed a retrospective study on 63 patients who 
Table 1

The risk of bias in the randomized controlled trials ${ }^{\mathrm{a}}$.

\begin{tabular}{|c|c|c|c|c|c|c|c|}
\hline Study & D1 & D2 & D3 & D4 & D5 & D6 & D7 \\
\hline Jain 2004 & Low & Low & Insufficient information & Low & Low & Low & Low \\
\hline Purushotham 2002 & Low & Low & Insufficient information & Low & Insufficient information & Low & Low \\
\hline
\end{tabular}

D1: Random sequence generation.

D2: Allocation concealment.

D3: Selective reporting.

D4: Blinding (participants and personnel).

D5: Blinding (outcome assessment).

D6: Incomplete outcome data.

D7: Other sources of bia.

a Measured with the Cochrane Risk of Bias Tool.

Table 2

The risk of bias in the non-randomized studies ${ }^{\mathrm{a}}$.

\begin{tabular}{|c|c|c|c|c|c|c|c|c|}
\hline Study & D1 & D2 & D3 & D4 & D5 & D6 & D7 & Overall \\
\hline Baker 2017 & Serious & Low & Serious & Low & Low & Low & Low & Serious \\
\hline Jackson 2019 & Moderate & Low & Serious & Low & No information & Low & Low & Serious \\
\hline Ouldamer 2015 & Low & Moderate & Low & Low & No information & Low & Low & Moderate \\
\hline Taylor 2013 & Critical & Low & Serious & Low & No information & Low & Low & Critical \\
\hline Ten Wolde 2019 & Moderate & Low & Serious & Low & Low & Low & Low & Serious \\
\hline Troost 2015 & Low & Low & Low & Low & Low & Low & Low & Low \\
\hline
\end{tabular}

D1: Bias due to confounding.

D2: Bias due to selection of participants.

D3: Bias in classification of interventions.

D4: Bias due to deviations from intended interventions.

D5: Bias due to missing data.

D6: Bias in measurement of outcomes.

D7: Bias in selection of the reported result.

a Measured with The Risk of Bias In Non-randomized Studies - of interventions (ROBINS-I) assessment tool.

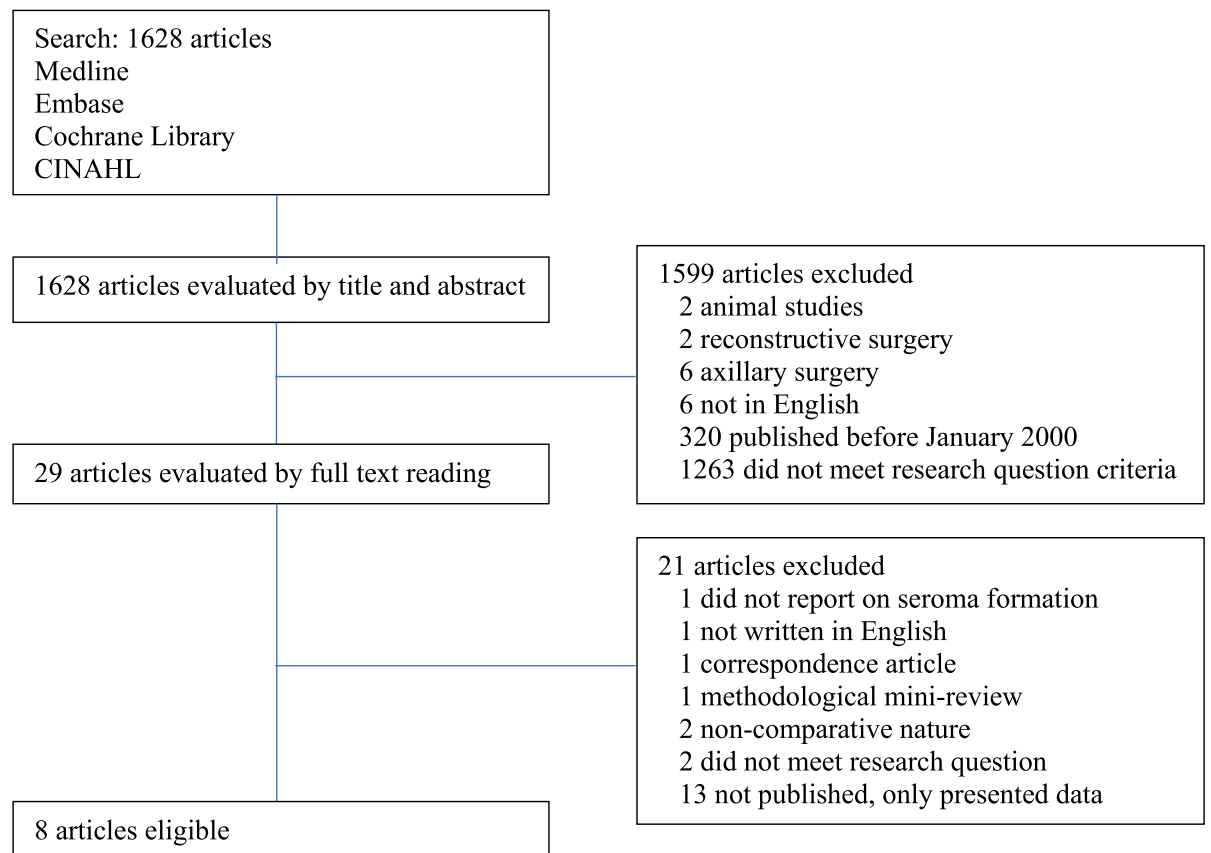

Fig. 1. Flowchart of the selection of eligible articles.

underwent mastectomy \pm sentinel lymph node biopsy (SLNB) or axillary sampling [9]. Of these patients, 39 patients received a drain during surgery and 24 did not. No flap fixation was performed. Demographics did not differ between the two groups. Criteria for assessing seroma formation were not defined. There was no significant difference in seroma formation between the drain group
(62\%) and the no-drain group (83\%) and there was a non-significant difference in seroma aspiration (drain: $46 \%$ vs. no drain: $67 \%$, $\mathrm{p}=0.113$ ). There was a significant difference in the average volume of drained seroma: $360 \mathrm{~mL}$ with drainage versus $725 \mathrm{~mL}$ without drainage $(\mathrm{p}=0.0096)$. There was no difference in wound infection ( $8 \%$ vs. $8 \%$ ). The authors state that drain-free mastectomy appears to 
Table 3

An overview of the drain free mastectomy studies with seroma incidence as outcome.

\begin{tabular}{|c|c|c|c|c|c|c|c|}
\hline Author & Study design & $\begin{array}{l}\text { No. of } \\
\text { patients }\end{array}$ & Procedure & Flap fixation and drains & $\begin{array}{l}\text { Seroma } \\
\text { formation } \\
\text { Drain vs. no } \\
\text { drain }\end{array}$ & $\begin{array}{l}\text { Symptomatic } \\
\text { seroma }^{\text {a }} \\
\text { Drain vs. no } \\
\text { drain }\end{array}$ & p-value \\
\hline Baker (2017) & Retrospective & 63 & Mastectomy \pm SLNB & Conventional closure with and without drain & $62 \%$ vs. $83 \%$ & $46 \%$ vs. $67 \%$ & NS \\
\hline Jackson (2019) & Prospective & 130 & Mastectomy \pm SLNB & Conventional closure with and without drain & $45 \%$ vs. $50 \%$ & $13 \%$ vs. $16 \%$ & NS \\
\hline Jain (2004) & RCT & 67 & MRM & $\begin{array}{l}\text { Conventional closure with drain }(n=36) \\
\text { Tissue glue without drain }(n=19) \\
\text { Conventional closure without drain }(n=12)\end{array}$ & - & $25 \%$ vs. $58 \%$ & 0.006 \\
\hline $\begin{array}{l}\text { Ouldamer } \\
\text { (2015) }\end{array}$ & Retrospective & 119 & $\begin{array}{l}\text { Mastectomy } \pm \text { SLNB or } \\
\text { ALND }\end{array}$ & $\begin{array}{l}\text { Conventional closure with drain and sutures without } \\
\text { drain }\end{array}$ & $52 \%$ vs $17 \%$ & $22 \%$ vs. $7 \%$ & $<0.001$ \\
\hline $\begin{array}{l}\text { Purushotham } \\
\quad \text { (2002) }\end{array}$ & RCT & 190 & MRM & $\begin{array}{l}\text { Conventional closure with } 2 \text { drains and sutures with } 1 \\
\text { drain }\end{array}$ & $55 \%$ vs. $61 \%$ & - & NS \\
\hline Taylor (2013) & Prospective & 431 & $\begin{array}{l}\text { Mastectomy } \pm \text { SLNB or } \\
\text { MRM }\end{array}$ & $\begin{array}{l}\text { Conventional closure with } 1 \text { drain and conventional } \\
\text { closure without drain }\end{array}$ & - & $57 \%$ vs $51 \%$ & NS \\
\hline $\begin{array}{l}\text { Ten Wolde } \\
\text { (2019) }\end{array}$ & Retrospective & 251 & Mastectomy \pm ALND & Sutures with drain and sutures without drain & - & $22 \%$ vs. $8 \%$ & 0.004 \\
\hline Troost (2015) & Retrospective & 96 & $\begin{array}{l}\text { Mastectomy } \pm \text { SLNB or } \\
\text { ALND, ALND }\end{array}$ & Conventional closure with drain and without drain & $91 \%$ vs. $85 \%$ & - & NS \\
\hline
\end{tabular}

\footnotetext{
a Symptomatic seroma defined as seroma that required intervention.
}

be safe but may require more frequent postoperative seroma aspirations.

Jackson et al. collected prospective data on 119 patients undergoing mastectomy with or without sentinel lymph node biopsy over sixteen months, resulting in 130 procedures [36]. Conventional wound closure without flap fixation was applied. Seroma formation did not differ between the drain (45\%) and no-drain group (50\%). Definition of seroma formation was not specified. Aspiration of seroma was performed in $12.5 \%$ of the patients with drain and $16 \%$ of the patients without drain $(p=0.803)$. The rate of wound infection was not different between groups (3\% vs. $4 \%$ ). The authors conclude that routine use of drains in patients undergoing simple mastectomy \pm SLNB may be unnecessary and costly.

Jain et al. performed a randomized clinical trial using drains and flap fixation using fibrin sealant following mastectomy with axillary lymph node dissection (ALND) [12]. Sixty-seven patients underwent mastectomy with ALND, with 36 patients randomized in the drain group (group I), and 31 patients in the no drain group. Of the latter, further randomization resulted in 19 patients receiving fibrin sealant (group II) and 12 patients without intervention (group III). Following mastectomy without a drain, the use of fibrin sealant compared to no flap fixation (group II vs. group III) was associated with a significant reduction in the incidence of seroma ( $42 \%$ vs. $83 \%$; $p=0.048$ ) as well as the total volume of seroma (190 ml vs. $395 \mathrm{ml} ; \mathrm{p}=0.012$ ). No significant difference in the incidence of seroma or total volume of aspirated seroma was found between patients in group I and II. Significantly more seroma was seen in the groups without drains when compared to the group with drains ( $25 \%$ vs. $58 \%$ respectively), irrespective of flap fixation.

Ouldamer et al. conducted a retrospective observational study of 119 patients who underwent mastectomy with or without SLNB or ALND [27]. Patients received either conventional closure with drainage ( $n=60$ ) or flap fixation using quilting sutures for wound closure without drainage $(n=59)$. However, if ALND was indicated, all patients received a drain in the axillary area after closure of this area with Vicryl sutures, regardless of how the mastectomy wound was managed. The primary outcome was symptomatic seroma which required medical intervention (type 2 or 3 seroma according to the common terminology criteria for adverse events classification (CTCAE) 4.0 [37]). Seroma, including asymptomatic seroma, was seen in $51.7 \%$ in the group with drainage and $17.0 \%$ in the group without drainage. Symptomatic seroma was observed in $21.7 \%$ (13/ $60)$ in the group with drainage and $6.8 \%(4 / 59)$ in the quilting suture group without drain in the pectoral area [odds ratio (OR) with quilting suture 0.26; confidence interval (CI), 0.08-0.86; $\mathrm{p}=0.03$. There was no significant difference in surgical site infection rate (drain $8.3 \%$ vs no drain $3.4 \%$, OR 0.39 (0.07-2.07), $\mathrm{p}=0.27$ ).

Purushotham et al. (2002) conducted a randomized clinical trial where 190 patients who underwent mastectomy (with level 2 axillary clearance) were allocated to either a control group with conventional wound closure and drainage $(n=96)$ or a group with flap fixation applying suturing of flaps and no drainage $(n=94)$ [28]. All patients had a drain in the axilla and only the control group with conventional wound drainage had a second drain under the mastectomy flaps. The superior and inferior flaps were sutured to the underlying pectoral muscle with parallel rows of $3 / 0$ vicryl sutures and in the axilla to the serratus anterior muscle. The proportion of patients developing seroma (drain: 55\% vs. no drain: $61 \%$ ) and wound infection (drain: $10 \%$ vs. no drain: $11 \%$ ) were similar in both groups. The criteria for seroma were however not well defined. The authors conclude that wound drainage following surgery for breast cancer surgery can be avoided.

Taylor et al. collected prospective data on 431 patients who underwent mastectomy with and without drainage [13]. Conventional wound closure without flap fixation was applied in both groups. Of the 247 patients who underwent mastectomy and ALND, 98 patients had no drain (39.7\%). Of the patients who underwent mastectomy with or without SLNB, this percentage was $66.3 \%$ (122) 184). The symptomatic seroma rates were equivalent with no statistically significant difference in both patient groups (mastectomy with ALND: drain $65.7 \%$ vs. no drain $64.3 \%$, mastectomy \pm SLNB: drain $35.5 \%$ vs. no drain $40.1 \%$ ). Symptomatic seroma was defined as a palpable fluid accumulation causing discomfort and requiring at least one aspiration. For both patient groups, the volume of seroma aspirated was significantly larger in the cohort without drainage (mastectomy with ALND: drain: $787 \mathrm{ml}$ vs. no drain: $1040 \mathrm{ml}$, $\mathrm{p}=0.013$, mastectomy \pm SLNB: drain $420 \mathrm{ml}$ vs. no drain $640 \mathrm{ml}$, $\mathrm{p}=0.030$ ). SSI rates were not significantly different ( $8 \%$ vs. $7 \%$ ). The authors state that these results suggest that mastectomy with or without SLNB or ALND can be performed without the use of suction drains without increasing seroma formation and other complication rates.

Ten Wolde et al. retrospectively compared two groups of patients $(\mathrm{n}=251)$ who underwent mastectomy, ALND or both [23]. The first group underwent flap fixation with quilting sutures and 
closed suction drainage ( $\mathrm{n}=85$ ), and the second group underwent flap fixation with quilting sutures without drainage $(n=166)$. The skin flaps were sutured to the underlying pectoral muscle with multifilament, size 0 sutures, applied in parallel evenly spaced rows. The quilting sutures were placed from cranial to caudal. Suturing of the latissimus dorsi muscle, the anterior serratus muscle, the subcutaneous tissue, and the lateral margin of the major pectoral muscle was performed. The patients without a postoperative drain had a lower incidence of symptomatic seroma when compared to the group with a postoperative drain (8.4\% vs. $21.2 \%$, $\mathrm{p}=0.004)$. Surgical site infection rate was similar in both groups (drain $9 \%$ vs. no drain $8 \%, \mathrm{p}=0.735$ ).

Troost et al. performed a retrospective cohort study $(n=96)$ and included patients who underwent mastectomy with or without SLNB or ALND, or ALND alone [14]. In the cohort, 44 patients were treated with a postoperative drain and 52 patients without postoperative drainage. Conventional wound closure without flap fixation was applied. No difference was found between both groups regarding frequency of seroma (drain $90.9 \%$ vs. no drain $84.6 \%$, $\mathrm{p}=0.290$ ) or SSI (drain $31.8 \%$ vs. no drain $21.2 \%, \mathrm{p}=0.235$ ). No criteria for assessing seroma formation were described.

Fig. 2 shows the forest plot of the meta-analysis of the effect of omitting drainage on the incidence of clinically significant seroma, defined as seroma requiring intervention. The studies of Troost et al. and Purushotham et al. were excluded for the forest plot as no data was available regarding seroma that required intervention. We observed substantial heterogeneity between studies (Isquared $=84 \%$ ). With an OR of 0.90 [0.42-1.94], it can be concluded that there is no statistically significant difference in symptomatic seromas when comparing mastectomy with or without drainage. In four of the studies flap fixation was performed. In two of these studies, the results favored drain-free mastectomy [23,27], one study was indifferent [28] and one study favored mastectomy with drainage [12].

\section{Discussion}

A limited number of studies have been published evaluating drain omission and the effect on seroma formation following mastectomy or modified radical mastectomy. We concluded that 8 articles were eligible for inclusion. Despite substantial study heterogeneity, the evidence that drainage can safely be omitted without increasing seroma formation seems convincing. Seroma formation incidence in this systemic review lies between $17 \%$ and $85 \%$ for patients without drain and between $45 \%$ and $91 \%$ for patients with drainage. Clinically significant seroma is seen in 7-67\% of the patients without drainage and in $13 \%-57 \%$ of the patients with drainage. Furthermore, omitting drainage does not seem to increase the SSI rate.

Two randomized controlled trials have been conducted on the matter of facilitating drain-free mastectomy [12,28]. Only one of these trials is well powered [28]. Although the results of Purushotham (2002) et al. are convincing, the main drawbacks of this study are the subjective reporting of seroma and two interventional differences between groups (drainage and flap fixation) [28]. One might consider this to be an unjust comparison, since in these studies two variables were changed, possibly causing bias. The remaining studies in this review support the findings of this randomized controlled trial, but are at risk for bias. Furthermore, the results of the forest plot in Fig. 2 should be carefully interpreted due to the substantial heterogeneity $\left(\mathrm{I}^{2}=84 \%\right)$. The evidence seems convincing that drainage can safely be omitted without increasing seroma formation, however, there are certain issues that need to be addressed.

As stated earlier, one of the difficulties in studies regarding seroma is the subjective method of reporting seroma formation. If no objective criteria are set for reporting seroma, a great variation in the incidence of seroma formation may result. With the subjective reporting of seroma, it becomes unclear if the observed effect of the intervention is a consequence of the intervention or due to observer bias. Moreover, small amounts of seroma have different implications when compared to large seromas requiring aspiration that are compromising wound healing. This subjective reporting of seroma was seen in 4 of the selected studies (Baker, Jackson, Purushotham and Troost), which might explain the relatively high incidence of seroma in these studies $[9,14,27,36]$. Of these studies, Baker et al. and Jackson et al. also reported on seroma aspiration $[9,36]$. Seroma aspiration seems to be a more objective outcome, however the indication for seroma aspiration must be well defined. This is generally not the case in retrospective studies. The remaining four studies (Jain, Ouldamer, Taylor and Ten Wolde) reported seromas that were regarded as clinically significant with predefined criteria [12,13,23,27]; these were all seromas requiring intervention. The method of reporting seroma is important to take into consideration when interpreting the results.

In all included studies, the incidence of SSI was not significantly different between the groups with and without closed suction drainage. All studies, except one, showed an incidence below $12 \%$ for SSI. Troost et al. found an incidence of SSI's between $21.2 \%$ and $31.8 \%$. This might be explained by the criteria used to report SSI's. In this study, antibiotic use or surgical interventions were not used as a criterium for defining SSI's. Clinical signs of infection (pain, swelling, erythema, fever, exudate, delayed wound healing or breakdown), purulent discharge or a positive microbiological culture were sufficient for being reported as SSI. These criteria were also used by Purushotham et al. (2002), but the incidence rate of SSI in their study was comparable to the other selected studies.

This review included all mastectomy patients, regardless of whether axillary lymph node dissection was performed. Axillary clearance has shown to be a predictor for seroma formation and

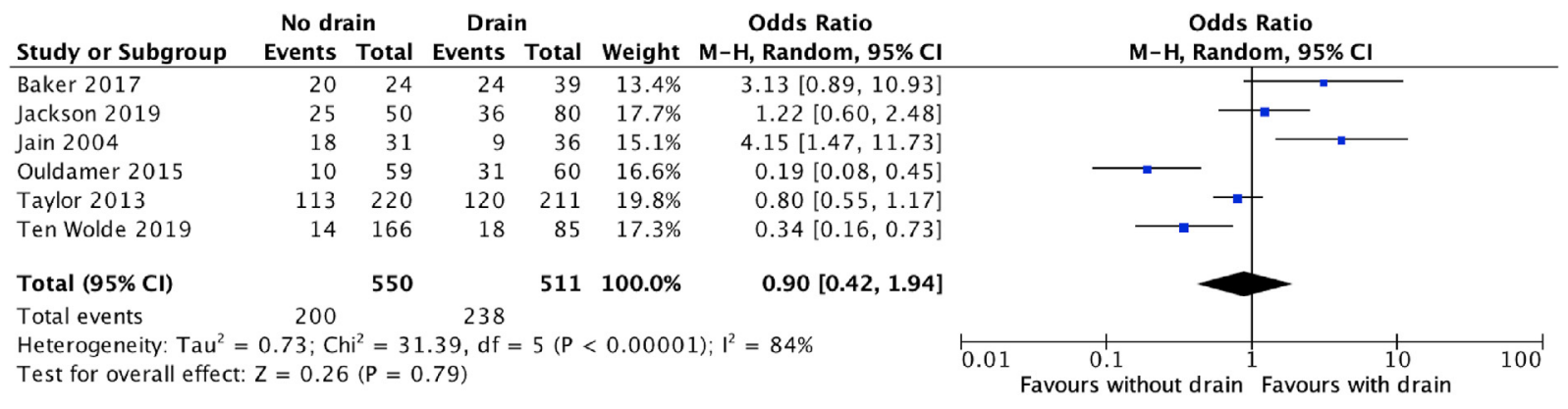

Fig. 2. Forest plot representing the effect of omitting drainage on clinically significant seroma*. 
seroma aspiration, with the highest incidence of seroma in patients undergoing modified radical mastectomy $[39,40]$. The distribution of the patients with or without axillary clearance in the studies might influence the results. Taylor et al. and Ten Wolde et al. performed a subgroup analysis based on procedure and found fewer symptomatic seromas in the patients without axillary clearance $[13,23]$. No subgroup analysis based on procedure was performed in the other two studies in which both patient groups were included $[14,27]$. Two studies decided to include patients undergoing axillary clearance alone $[14,23]$. One might argue that axillary clearance alone, is a procedure that differs from simple mastectomy or modified radical mastectomy and should be excluded in this review. Considering the fact that axillary clearance is a predictor of seroma formation, the surgical management of the axillary area in the studies including patients that underwent axillary clearance is of great importance. Careful reading brings to light that Purushotham et al. only omitted drainage of the pectoral area [28]. Thus, all patients in that study received a drain in the axillary area. The same procedure was performed in the patients undergoing axillary clearance in the study conducted by Ouldamer et al. [27]. Different methods of management of the axillary area might influence the results.

In recent years, mastectomy with flap fixation is upcoming and is slowly gaining popularity amongst breast cancer surgeons. Several studies on flap fixation techniques have shown promising results in reducing the incidence and aspirations of seroma after breast cancer surgery [20-26]. Mastectomy with flap fixation is currently more often than not combined with closed suction drainage. Of the selected studies, 4 studies performed flap fixation combined after mastectomy (Jain, Ouldamer, Purushotham and Ten Wolde) $[12,23,27,28]$, of which only Ten Wolde et al. applied flap fixation (sutures) in all patients [23]. In the other three studies, flap fixation was only performed in the group without closed suction drainage. A recent randomized controlled trial performed by our research group has revealed that closure of the dead space reduces seroma formation, albeit in the presence of closed suction drainage [38].

\section{Conclusion}

Despite substantial heterogeneity in the included studies, it may be concluded that there is some evidence that drainage after mastectomy with or without SLNB/ALND can safely be omitted without increasing seroma formation and seroma associated complications. The relative importance of flap fixation and drainage in the prevention of seroma and seroma related complications has not yet been well studied. Further research is required to establish the management of the post-mastectomy space with the highest chance to avoid seroma and its complications/sequelae. Our research group has started a randomized controlled trial (the SARA trial) to evaluate the effect of omitting closed suction drainage on seroma formation in patients undergoing mastectomy with flap fixation. The SARA Trial is registered at ClinicalTrials.gov, Identifier: NCT04035590.

\section{Disclosure of potential conflicts of interest}

All authors declare that they have no conflict of interest and that no funding was involved.

\section{Ethical approval}

This article does not contain any studies with human participants or animals performed by any of the authors.

\section{Informed consent}

No individual participants were included in this study.

\section{Data availability}

Data sharing not applicable to this article as no datasets were generated or analyzed during the current study. However, the literature search of each database is available upon reasonable request.

\section{Author contributions}

$\mathrm{LdR}, \mathrm{AB}$ and JvB had the idea for the review and performed the literature search. LdR, AB and SvK performed data analysis. JvB, SvK, YV and GB critically revised the work.

\section{Declaration of competing interest}

The authors declare that they have no known competing financial interests or personal relationships that could have appeared to influence the work reported in this paper.

\section{References}

[1] Agrawal A, Ayantunde AA, Cheung KL. Concepts of seroma formation and prevention in breast cancer surgery. ANZ J Surg 2006;76(12):1088-95.

[2] Van Bemmel AJ, van de Velde CJ, Schmitz RF, Liefers GJ. Prevention of seroma formation after axillary dissection in breast cancer: a systematic review. Eur J Surg Oncol 2011;37(10):829-35.

[3] Kuroi K, Shimozuma K, Taguchi T, Imai H, Yamashiro H, Ohsumi S, et al. Effect of mechanical closure of dead space on seroma formation after breast surgery. Breast Cancer 2006;13:260-5.

[4] Gong Y, Xu J, Shao J, Cheng H, Wu X, Zhao D, et al. Prevention of seroma formation after mastectomy and axillary dissection by lymph vessel ligation and dead space closure: a randomized trial. Am J Surg 2010;200(3):352-6.

[5] Kumar S, Lal B, Misra MC. Post-mastectomy seroma: a new look into the aetiology of an old problem. J R Coll Surg Edinb 1995;40:292-4.

[6] Woodworth PA, McBoyle MF, Helmer SD, Beamer RL. Seroma formation after breast cancer surgery; incidence and predicting factors. Am Surg 2000;66(5): 444-50.

[7] Carless PA, Henry DA. Systematic review and meta-analysis of the use of fibrin sealant to prevent seroma formation after breast cancer surgery. Br J Surg 2006;93(7):810-9.

[8] Somers RG, Jablon LK, Kaplan MJ, Sandler GL, Rosenblatt NK. The use of closed suction drainage after lumpectomy and axillary node dissection for breast cancer. Ann Surg 1992;215(2):146-9.

[9] Baker E, Piper J. Drainless mastectomy: is it safe and effective? Surgeon 2017; 15(5):267-71.

[10] Stoyanov GS, Tsocheva D, Marinova K, Dobrev E, Nenkov R. Drainage after modified radical mastectomy -. Methodol. Mini-Rev. 2017;9(7):e1454.

[11] Zaidi S, Hinton C. Breast cancer surgery without suction drainage and impact of mastectomy flap fixation in reducing seroma formation. Eur J Surg Oncol 2017;43:S32.

[12] Jain PK, Sowdi R, Anderson AD, MacFie J. Randomized clinical trial investigating the use of drains and fibrin sealant following surgery for breast cancer. Br J Surg 2004;91:54-60.

[13] Taylor JC, Rai S, Hoar F, Brown H, Vishwanath L. Breast cancer surgery without suction drainage: the impact of adopting a 'no drains'policy on symptomatic seroma formation rates. Eur J Surg Oncol 2013;39(4):334-8.

[14] Troost MS, Kempees CJ, de Roos MAJ. Breast cancer surgery without drains: No influence on seroma formation. Int J Surg 2015 Jan;13:170-4.

[15] Barwell J, Campbell L, Watkins RM, Teasdale C. How long should suction drains stay in after breast surgery with axillary dissection? Ann R Coll Surg Engl 1997;79:435-7.

[16] Gupta R, Pate K, Varshney S, Goddard J, Royle GT. A comparison of 5-day and 8-day surgical drainage following mastectomy and axillary clearance. Eur J Surg Oncol 2001;27:26-30.

[17] Kottayasamy Seenivasagam R, Gupta V, Singh G. Prevention of seroma formation after axillary dissection-a comparative randomized clinical trial of three methods. Breast J 2013 Sep-Oct;19(5):478-84.

[18] Van Bastelaar J, van Roozendaal L, Granzier R, Beets G, Vissers Y. A systematic review of flap fixation techniques in reducing seroma formation and its sequelae after mastectomy. Breast Canc Res Treat 2018 Jan;167(2):409-16.

[19] Van Bastelaar J, Theunissen LLB, Snoeijs M, Beets G, Vissers Y. Flap fixation using tissue glue or sutures appears to reduce seroma aspiration after mastectomy for breast cancer. Clin Breast Canc 2017 Jul;17(4):316-21. 
[20] Ko E, Han W, Cho J, Lee JW, Kang SY, Jung SY, et al. Fibrin glue reduces the duration of lymphatic drainage after lumpectomy and level II or III axillary lymph node dissection for breast cancer: a prospective randomized trial. J Kor Med Sci 2009 Feb;24(1):92-6.

[21] Almond LM, Khodaverdi L, Kumar B, Coveney EC. Flap anchoring following primary breast cancer surgery facilitates early hospital discharge and reduces costs. Breast Care (Basel) 2010;5(2):97-101.

[22] Sakkary MA. The value of mastectomy flap fixation in reducing fluid drainage and seroma formation in breast cancer patients. World J Surg Oncol 2012;10: 8.

[23] Ten Wolde B, van den Wildenberg FJ, Keemers-Gels ME, Polat F, Strobbe LJ. Quilting prevents seroma formation following breast cancer surgery: closing the dead space by quilting prevents seroma following axillary lymph node dissection and mastectomy. Ann Surg Oncol 2014;21:802-7.

[24] Benevento R, Santoriello A, Pellino G, Sciaudone G, Candilio G, De Fatico GS, et al. The effects of low-thrombin fibrin sealant on wound serous drainage, seroma formation and length of postoperative stay in patients undergoing axillary node dissection for breast cancer. A randomized controlled trial. Int J Surg 2014 Nov;12(11):1210-5.

[25] Eichler C, Fischer P, Sauerwald A, Dahdouh F, Warm M. Flap adhesion and effect on postoperative complication rates using Tissuglu $($ in mastectomy patients. Breast Cancer 2016;23:486-90.

[26] Vasileiadou K, Kosmidis C, Anthimidis G, Miliaras S, Kostopoulos I, Fahantidis E. Cyanoacrylate adhesive reduces seroma production after modified radical mastectomy or quadrantectomy with lymph node dissection-A prospective randomized clinical trial. Clin Breast Canc 2017 Dec;17(8):595-600.

[27] Ouldamer L, Caille A, Giraudeau B, Body G. Quilting suture of mastectomy dead space compared with conventional closure with drain. Ann Surg Oncol 2015 Dec;22(13):4233-40.

[28] Purushotham AD, McLatchie E, Young D, George WD, Stallard S, Doughty J, et al. Randomized clinical trial of no wound drains and early discharge in the treatment of women with breast cancer. Br J Surg 2002 Mar;89(3):286-92.

[29] Liberati A, Altman DG, Tetzlaff J, Mulrow C, Gøtzsche PC, Ioannidis JP, et al. The
PRISMA statement for reporting systematic reviews and meta-analyses of studies that evaluate health care interventions: explanation and elaboration. PLoS Med 2009 Jul 21;6(7):e1000100. https://doi.org/10.1371/journal.pmed.1000100. Epub 2009 Jul 21.

[30] Higgins JPT, Green S, editors. Cochrane handbook for systematic reviews of interventions. Cochrane Collaboration Tool. Wiley; 2008.

[31] Sterne JAC, Hernán MA, Reeves BC, Savović J, Berkman ND, Viswanathan M, et al. ROBINS-I: a tool for assessing risk of bias in non-randomized studies of interventions. BMJ 2016;355:i4919. https://doi.org/10.1136/bmj.i4919.

[32] Higgins JP, Thompson SG, Deeks JJ, Altman DG. Measuring inconsistency in meta-analyses. BMJ 2003 Sep 6;327(7414):557-60.

[33] Purushotham AD, McLatchie E. Avoiding wound drainage in surgery for primary breast cancer. Breast 1998;7:227-8.

[34] Eichler C, Dahdouh F, Fischer P, Warm M. No-drain mastectomy - preventing seroma using TissuGlu(®): a small case series. Ann Med Surg (Lond). 2014 Aug $7 ; 3(3): 82-4$.

[35] Ebner FK, Friedl TW, Degregorio N, Reich A, Janni W, Rempen A. Does nonplacement of a drain in breast surgery increase the rate of complications and revisions? Geburtshilfe Frauenheilkd 2013 Nov;73(11):1128-34.

[36] Jackson PC, Macinnes EG, Nicholson JK, Brayshaw I, Relton S, Achuthan R, July 17. Mastectomy without drains reduces cost with No detriment to patient outcome. Cureus 2019;11(7):e5160.

[37] https://www.eortc.be/services/doc/ctc/CTCAE_4.03_2010-06-14 QuickReference_5x7.pdf. [Accessed 13 January 2020]. Accessed on.

[38] Granzier RWY, van Bastelaar J, van Kuijk SMJ, Hintzen KFH, Heymans C, Theunissen LLB, et al. Reducing seroma formation and its sequelae after mastectomy by closure of the dead space: the interim analysis of a multicenter, double-blind randomized controlled trial (SAM trial). Breast 2019 Aug;46:81-6.

[39] Hashemi E, Kaviani A, Najafi M, Ebrahimi M, Hooshmand H, Montazeri A. Seroma formation after surgery for breast cancer. World J Surg Oncol 2004 Dec 9;2:44.

[40] Gonzalez EA, Saltzstein EC, Riedner CS, Nelson BK. Seroma formation following breast cancer surgery. Breast J 2003 Sep-Oct;9(5):385-8. 